\title{
TRADUÇÃO ANOTADA, AUTOR-TRADUTOR INVISIVEL: RICHARD FRANCIS BURTON NA BRASILIANA
}

\author{
Cristina Carneiro Rodrigues*
}

RESUMO: Este trabalho tem como objetivo analisar a tradução da obra do viajante e tradutor Richard Francis Burton Explorations of the Highlands of the Brazil with a full account of the gold and diamond mines, assinada por Américo Jacobina Lacombe, buscando relacionar seu trabalho às metas editoriais da Coleção Brasiliana. Subsérie da Biblioteca Pedagógica Brasileira, da Companhia Editora Nacional, a Brasiliana foi concebida em sintonia com a política dos anos 30 e 40, de expandir a educação laica e de fazer com que os brasileiros conhecessem melhor a grandeza do Brasil. O exame vai enfocar as numerosas notas do tradutor, pois é em parte delas que Lacombe revela seu propósito didático de informar seus leitores sobre a história e a geografia do país. A análise focaliza, ainda, o apagamento do trabalho de tradução do português para o inglês que Burton pratica em sua obra.

UNITERMOS: Richard Francis Burton; Américo Jacobina Lacombe; Coleção Brasiliana; relato de viagem; notas de rodapé.

ABSTRACT: The aim of this paper is to analyze the translation of the work by the translator-traveller Richard Francis Burton, Explorations of the Highlands of the Brazil, with a full account of the gold and diamond mines, made

* UNESP - Universidade Estadual Paulista. cristina@ibilce.unesp.br

TradTerm, 17, 2010, p. 67-84 
by Américo Jacobina Lacombe, trying to relate the work of the latter to the editorial goals of the Brasiliana Collection. As a subseries of the Biblioteca Pedagógica Brasileira [Brazilian Pedagogical Library] published by Companhia Editora Nacional, Brasiliana was conceived in agreement with the 1930s and 1940s policies to expand lay education and make it possible for Brazilians to get to better know the greatness of their country. The paper will focus on the numerous translator's notes, since many of them reveal Lacombe's didactic purpose of informing readers about Brazilian history and geography. The analysis also examines the effacement of Burton's translations from Portuguese into English in his book.

KEYWORDS: Richard Francis Burton; Américo Jacobina Lacombe; Brasiliana Collection; travel writing; footnotes.

\section{Contextualizando}

Os anos 30 foram marcados por um projeto de modernização do Brasil, do qual fazia parte a expansão da educação por meio de reformas do ensino primário e secundário e da criação de universidades e novas faculdades. Como consequência, aumenta a procura por livros de ficção e didáticos, o que gera a expansão do mercado editorial. Alguns intelectuais brasileiros, acreditando na capacidade transformadora e pedagógica da palavra escrita, envolvem-se no ramo editorial e projetam coleções com "o objetivo explícito de apresentar o debate político dos anos 30 " ou com a meta de "revelar os aspectos mais variados da realidade brasileira" (Pontes 1989: 369).

Entre as coleções do segundo grupo está a Brasiliana, publicada a partir de 1931 pela Companhia Editora Nacional. Os livros selecionados para a coleção eram estudos sobre a realidade nacional e buscavam "reunir um conhecimento sistemático sobre o Brasil" (Dutra 2006: 301), dar-1he um sentido de conjunto e apontar caminhos para o futuro.

De acordo com De Luca (1999: 90-92), nas duas décadas precedentes, reiterava-se a ideia de que o Brasil era um país

TradTerm, 17, 2010, p. 67-84 
novo, em construção, mas apto a inovar e a solucionar seus problemas - desde que se conhecesse. A intelectualidade brasileira busca, especialmente a partir de meados da década de 1910, diagnosticar problemas e conhecer melhor a história, a geografia e a população do Brasil. A Revista do Brasil, da qual Monteiro Lobato foi editor e proprietário, em parceria com Octales Marcondes Ferreira, foi o maior veículo dos trabalhos dirigidos a divulgar os novos conhecimento sobre o Brasil e lutar contra a ignorância, o preconceito, buscando "livrar a nação dos males que a corroíam" (De Luca 1999: 216).

Em 1925, Octales Marcondes Ferreira, em sintonia com os ideais de sua época, funda, com Monteiro Lobato, a Companhia Editora Nacional. Em 1931, Fernando de Azevedo é encarregado de organizar a Biblioteca Pedagógica Brasileira ${ }^{1}$. Uma das cinco subséries da Biblioteca, a Coleção Brasiliana, dirigida por Fernando de Azevedo entre 1931 e 1958, tanto relaciona-se à renovação escolar quanto à divulgação da cultura e do pensamento brasileiro. Lê-se, na orelha da contracapa de algumas obras publicadas, que a Brasiliana "é a mais vasta e completa coleção e sistematização que se tentou, até hoje, de estudos brasileiros". Consta também a informação de que a série se compõe de "ensaios sobre a formação histórica e social do Brasil; de estudos de figuras nacionais e de problemas brasileiros (históricos, geográficos, etnológicos, políticos, econômicos etc.); de reedições de obras raras e de notório interesse e de traduções de obras estrangeiras sobre assuntos brasileiros" (grifos meus) ${ }^{2}$. A Coleção Brasiliana não publica, portanto, apenas obras de intelectuais brasileiros. Dentre as traduções, privilegiam-se relatos

1 De acordo com Pontes (1989, p. 388), Octales Marcondes Ferreira, fundador da Companhia Editora Nacional, encarregou Fernando de Azevedo de organizar a Biblioteca Pedagógica Brasileira. Azevedo integrou o movimento pela reforma do ensino e participou do movimento de fundação da Universidade de São Paulo, tendo sido diretor da Faculdade de Filosofia, Ciências e Letras (1941-42).

2 A maior parte dos volumes a que tive acesso não mais possuem as orelhas; nos que ainda as conservam, muitos publicam, nessa posição, a continuação da orelha da capa, ou seja, a apresentação da obra. O texto citado foi retirado do v. 292, de 1957.

TradTerm, 17, 2010, p. 67-84 
de cronistas e viajantes estrangeiros, "sobretudo daqueles que, através de expedições científicas, percorreram o país ao longo do século XIX" (Pontes 1989: 392). Pontes (Ibid: 392) considera intrigante que, nesse "movimento de 'redescoberta' do Brasil", de "debate sobre a questão da cultura e da identidade nacional", se publiquem relatos de cronistas e viajantes. Para a autora, entretanto, a edição de obras dessa natureza passa a fazer sentido se pensarmos que elas poderiam oferecer "conhecimento seguro" sobre aspectos do Brasil e teriam se tornado "fonte obrigatória de consulta para todos os que se propunham a interpretálo" (Pontes 1989: 393) ${ }^{3}$.

Em seu trabalho sobre a Revista do Brasil, Tania De Luca (1999: 47) aponta que os assuntos dos textos nela publicados entre os anos 20 e 43, buscam compreender o Brasil como nação - "dar um sentido de conjunto ao país" - e apontar caminhos para seu futuro. Uma característica em comum com a Coleção Brasiliana é publicar relatos de viagem. De Luca chama também a atenção para o destaque dado, na revista, para o discurso sobre o espaço geográfico: a gigantesca dimensão do Brasil seria alvo de orgulho nacional. Os relatos de viajantes, além do conhecimento científico, evidenciariam também a pluralidade de costumes, a diversidade de paisagens e a extensão territorial do Brasil.

Minha análise de uma dessas obras indica, entretanto, que não é apenas esse "conhecimento seguro" e a divulgação da cultura de diversas regiões que estão em questão. O avanço do conhecimento sobre o país e as mudanças ocorridas entre o período em que o viajante esteve no Brasil e a publicação da obra na Coleção Brasiliana também estão em pauta - e em sintonia com a política governamental de ampliar o conhecimento dos leitores sobre o Brasil.

3 De acordo com Pontes, (1989, p. 391), dos 307 títulos editados entre 1931 e 1960, 45 eram relatos de cronistas e viajantes. Como a autora não tem a preocupação de distinguir obras em português de traduções, fiz um levantamento e verifiquei que, dos 316 livros publicados na primeira fase da coleção, apenas 25 são relatos de viagem traduzidos. Há outras traduções, de assuntos como antropologia, história, geografia, botânica.

TradTerm, 17, 2010, p. 67-84 


\section{O viajante Richard Burton e o tradutor Américo} Jacobina Lacombe

O relato selecionado para publicação no volume 197 da Coleção Brasiliana foi o do viajante e tradutor Richard Francis Burton. A serviço do governo britânico, Burton foi cônsul em Santos e estabeleceu residência na cidade de São Paulo de 1865 a 1868. "Depois de dezoito meses tediosos em Santos", Lord Stanley, então Secretário de Sua Majestade para os Negócios Exteriores, concedeu-lhe licença para que se ausentasse de seu posto. A viagem teria uma parte oficial, com o propósito de inspecionar minas de diamantes e outra parte, de férias, em que Burton realizaria o projeto pessoal de descer o rio São Francisco de barco até a cachoeira de Paulo Afonso (Burton 1976: 35). O relato dessa viagem foi publicado em Londres em 1869, como Explorations of the highlands of the Brazil with a full account of the gold and diamond mines.

A tradução foi feita por Américo Jacobina Lacombe e publicada em três volumes, o primeiro deles em 1941. Lacombe, professor, historiador, biógrafo e ensaísta, foi Secretário do Conselho Nacional de Educação de 1931 a 1939, participou do grupo que lançou as bases da Pontificia Universidade Católica do Rio de Janeiro, onde, a partir de 1941, lecionou História do Brasil. De 1939 a 1967 foi o Diretor da Casa de Rui Barbosa e substituiu Fernando Azevedo na direção da Coleção Brasiliana em 1958. Seus dados biográficos indicam que Lacombe tanto fazia parte do movimento pela reforma educacional do Brasil, como era uma pessoa afinada com a política editorial da Coleção Brasiliana.

Tomando como base a contextualização acima, pretendo analisar a tradução assinada por Américo Jacobina Lacombe, buscando evidenciar, por um lado, como seu trabalho relaciona-se com as metas da Coleção Brasiliana de, como consta do Catálogo Brasiliana Comemorativo dos 200 volumes (1941, apud Dutra 2006: 305) "descobrir o Brasil aos brasileiros, torná-lo cada vez mais conhecido para o fazer mais amado". Por outro lado, tem como objetivo demonstrar que há, no trabalho de Lacombe, propósito didático em sintonia com as políticas governamentais. O exame vai enfocar as numerosas notas do tradu- 
tor, pois elas assinalam uma intervenção explícita no texto a que os leitores têm acesso.

Saliento que sempre, em um texto, o tradutor revela sua interpretação. Isso significa que tradutor algum pode ser invisível, mesmo quando deseja apagar-se. Apesar de amplamente citado, parece conveniente repetir que, de acordo com Rosemary Arrojo (1992: 68),

toda tradução, por mais simples e breve que seja, trai sua procedência, revela as opções, as circunstâncias, o tempo e a história de seu realizador. Toda tradução, por mais simples e breve que seja, revela ser produto de uma perspectiva, de um sujeito interpretante e, não, meramente, uma compreensão "neutra" e desinteressada ou um resgate comprovadamente "correto" ou "incorreto" dos significados supostamente estáveis do texto de partida.

Nesse caso, o professor e historiador Américo Jacobina Lacombe revela, tanto em seu texto quanto em suas notas, os sentidos por ele produzidos, seu conhecimento da história do Brasil e seu propósito didático.

\section{As notas}

Nessa tradução, como em outras da Coleção Brasiliana, a visibilidade é patente pela característica das notas e por sua quantidade, especialmente na segunda edição, de 1983. Meu objetivo não é quantificação, mas procedi a uma contagem das notas dos quinze primeiros capítulos do primeiro tomo do relato, para dar uma noção da profusão de notas na segunda edição e de sua diferença em relação à primeira: nas 199 páginas da primeira edição, contei cerca de 170 notas de Burton e 17 de Lacombe; nas 155 páginas da segunda edição, localizei 80 de Lacombe. No texto de partida são todas de fim de página, assim como na primeira edição da tradução; as notas de Burton só são assinaladas com N. A., nota do autor; quando seguidas por uma N. T., trata-se de notas do tradutor. Na segunda edição, são numeradas consecutivamente, no final de cada capítulo, e in-

TradTerm, 17, 2010, p. 67-84 
troduzidas por N.A. ou por N.T.; quando ambos apõem notas, há apenas um número para uma N.A. e uma N.T ${ }^{4}$.

Para esta exposição, classifiquei as notas de Lacombe em quatro grupos. Como explicarei a seguir, não são tipos estanques, pois, como a classificação é dependente da interpretação do texto, muitas delas podem ser híbridas ou apresentar características semelhantes às de outros grupos. Três deles, o das notas explicativas ou informativas, o das complementares e o das retificadoras comprovam o objetivo da Brasiliana de ampliar o conhecimento de seus leitores sobre o Brasil e os brasileiros. É mais dificil determinar a função do quarto grupo de notas, pois apenas remetem a "em português no original". Em minha análise falta ainda um quinto grupo de notas: as que informariam que Burton traduz, para seu leitor inglês, rimas, canções, poemas que os brasileiros leem em português.

\section{As notas explicativas}

Explicativas ou informativas, parte das notas de Lacombe cientifica quem é um indivíduo mencionado por Burton, a data em que um fato relatado ocorreu, o nome científico de uma planta ou animal. São numerosas na segunda edição, mas poucas na primeira. Há um exemplo interessante no terceiro capítulo, em que Burton relata a viagem feita de Juiz de Fora a Barbacena. Ao passar pela Serra das Abóboras, "uma curiosidade local" desperta sua atenção e Burton assinala, em nota, as especificidades da Pedra da Fortaleza, conforme descrita por Castelnau. Lacombe acrescenta, em N. T.5:

4 Talvez por questões de normatização, na primeira edição há espaço depois do ponto, inexistente na segunda. Por certo periodo, a ABNT determinou que não se colocasse espaço após ponto; na NBR 6023:2002, determina-se que haja espaço após ponto.

5 De acordo com Rice (1999), Burton preparava com antecedência suas viagens. Nessa obra fica muito evidente o que significava a preparação de uma viagem pois, ao final de seu "Ensaio Preliminar", há uma extensa relação bibliográfica evidenciando que Burton leu os livros vários de viajantes que, antes dele, passaram pelo Brasil, assim como gramáticas, dicionários de tupi e atlas (Burton, 1941: 43-53).

TradTerm, 17, 2010, p. 67-84 
Refere-se o autor ao famoso Eozoon canadenses, que Dawson julgou decobrir em alguns fosseis laurencianos, fato contestado pela maioria dos geólogos. Orville Derby encontrou em Alagoas, junto a Paulo Afonso, uma formação calcárea semelhante (N. T.). (Burton, 1941: 93) ${ }^{6}$

As notas explicativas teriam caráter didático, informativo. Mas, nessa nota, é muito evidente a dispersão de sentidos. Ao mesmo tempo em que o tradutor quer especificar de que o autor trata, remete a outro assunto e a outras referências.

No mesmo capítulo, na segunda edição, há uma nota com característica semelhante. Burton discorre, no texto, a respeito da nova estrada ligando Petrópolis a Minas Gerais e acrescenta uma nota, para explicar quem foram os engenheiros que trabalharam no projeto e salientar que o viajante Agassiz apenas se referiria aos engenheiros franceses, deixando de informar o nome dos brasileiros envolvidos. Burton finaliza a nota com a seguinte afirmação: "no Brasil freqüentemente os estrangeiros alegam ou procuram arrebatar as honras devidas aos nacionais" (Burton, 1983:111); o texto de Lacombe que segue, é uma ruptura em relação à nota de Burton, pois explica quem foram os engenheiros a que o autor se refere no texto e especifica qual companhia construiu a estrada e fornece o nome de seu presidente, vicepresidente, secretário e tesoureiro; os engenheiros franceses mencionados por Agassiz também são nomeados. Há excesso de informação, perdendo-se o ponto assinalado por Burton: a tendência de os viajantes assinalarem os feitos dos estrangeiros, deixando de apontar as obras dos brasileiros.

A explicação, nesse caso e em outros constatados na segunda edição, em lugar de controlar e fechar os sentidos, como em geral se comenta sobre notas de rodapé, funciona como dispersão e produção de novos sentidos.

6 Optei por manter a grafia, a pontuação e os destaques exatamente como estão nos textos consultados em todos os exemplos. O texto em inglês é apresentado em itálico, de acordo com as normas; assim, os caracteres que estiverem em fonte normal estavam em itálico no texto de partida. Sublinharei os meus destaques, porque o sublinhado não é recurso utilizado nas edições consultadas.

TradTerm, 17, 2010, p. 67-84 
Há, entretanto, casos em que o esclarecimento do tradutor tem função didática mais explícita. Por exemplo, no trecho em que Burton descreve o processo de produção da cachaça, diz que o óleo não removido da superficie teria "gosto de cobre e fumaça - não Glenlivet"; Lacombe apõe nota explicando "Glenlivet": "Whisky escossês, que tem o nome do lugar em que se fabrica. (N. T.)" (Burton, 1941: 306). Não explica, entretanto, a relação que se estabelece entre o uísque e "gosto de cobre e fumaça”, ou seja, o didatismo tem seus limites.

\section{As notas complementares}

Acrescentam sentidos, complementam o dito de Burton. Por exemplo, o autor, ao descrever os campos por onde passa, observa que "a typical feature in these Prairie lands is that which Minas calls 'esbarrancado', and São Paulo 'vossoroca" (Burton, 1869:73) e explica as palavras em português em nota; na tradução lê-se que um aspecto "característico desses campos é o que em Minas se chama 'esbarrancado' e em São Paulo 'vossoroca”, sem qualquer indicação de que as palavras estariam em português. A nota explicativa de Burton é traduzida e Lacombe acrescenta: "em São Paulo encontra-se a expressão 'Mossoroca' - (Amparo) - Otoniel Mota registra a formosa Bossoroca-Rev. Brasil, n. 40 (N. T.)" (Burton, 1941: 135).

Essas notas são muito comuns especialmente quando Burton se refere a animais ou plantas. Por exemplo, o autor encanta-se com "the Bombax (Paineira)" e, em nota, explica como são seus frutos e afirma existirem outras espécies da árvore no Brasil e na África, citando apenas uma delas, a "Chorisia or Bombax ventricosa" (Burton, 1869: 157). Lacombe adiciona a seguinte informação: "são tres as espécies conhecidas: Chorisia speciosa (St. Hil.), chorisia bombacacea e c. crispiflora (H. B. K.) - (N. T.)" (Burton, 1941: 257). Seu caráter é didático: trazer mais conhecimento ao leitor da Coleção Brasiliana, instruí-lo com o que se conhece além do que se sabia na época da viagem de Burton.

Algumas notas complementares, no entanto, parecem pressupor um leitor ignorante. Por exemplo, em Congonhas do Cam-

TradTerm, 17, 2010, p. 67-84 
po, Burton lista, em nota de rodapé, os doze apóstolos cujas estátuas estão nas escadarias da igreja. Após listá-los, acrescenta, ironicamente, que "all agree that the statues are twelve, yet in a memorandum given to me I find them thus described: to the right Ezequiel, Habbakuk, Hosea, Joel and Nahum; on the left Baruch, Daniel, Jonah, Amos, and Obadiah" (Burton, 1869: 171). Esse trecho é traduzido como "todos dizem que as estátuas são doze, mas numa nota que me deram assim os encontro descritos: à direita Ezequiel, Habacuc, Oséas, Joel e Naúm; à esquerda Baruc, Daniel, Jonas, Amos, e Abdias. (N. A.)". Abaixo, lê-se: "faltam, nesta nota os nomes de Isaias e Jeremias. (N. T.)" (Burton, 1941: 276). Esse acréscimo desnecessário indica que o tradutor parte do pressuposto de que seus leitores não seriam capazes de recuperar a informação prestada no início da nota e buscar por si mesmos os nomes dos apóstolos que faltavam. Talvez seja um indício de paternalismo por parte do tradutor, o que não está exatamente de acordo com os supostos leitores da Coleção Brasiliana, que seria dirigida às elites brasileiras da época.

\section{As notas retificadoras}

São as notas em que Lacombe corrige a informação dada por Burton, ou a ortografia usada. Em muitas delas a retificação é disfarçada de complementação, como no seguinte caso, em que Burton apõe uma nota a "Poaya, a kind of Ipecacuanha" (Burton, 1869: 164):

Poaya is in the Brazil a generic term for this species of Rubiaceæ. The true emetic root is distinguished as Poaya Verdadeira, or de botica - of apothecary's shop. The System derives "ipecacuanha" from ipé-caá-goéne, "the little plant near the roads:" it is rather "the little plant which excites emetism" (goéne) and doubtless the wild mediciners well know its use. Being much used in certain feminine complaints, it may mean "the little plant of the woman" (Cunha). The word has been corrupted to Epicaquenha and Picahonha. There are many kinds, the Ipecacuanha-

TRadTerm, 17, 2010, p. 67-84 
preta (I. officinalis arruda); the I. branca (Viola Ipecacuanha, or Pombalia Ipecacuanha Vandelli).

A poaia é, no Brasil, um termo genérico para esta espécie de rubiácea. A verdadeira raiz emética é conhecida como Poaia Verdadeira, ou de botica. O Sistema deriva ipecacuanha de ipé- caá-goéne, "a plantinha perto dos caminhos" é antes a "plantinha que provoca emetismo (goéne), e sem dúvida os médicos selvagens conhecem bem o seu uso. Sendo muito usada em alguns incômodos femininos, pode bem significar "a plantinha da mulher" (cunha). A palavra se corrompeu em Epicaquenha e Picahonha. Há várias espécies, Ipecacuanha-preta (I. officinalis arruda); a I. branca (Viola Ipecacuanha, ou Pombalia Ipecacuanha Vandelli). (N. A.)

Há, de fato, várias espécies pertencentes às famílias das rubiáceas, meliáceas, vitáceas, ascepiadáceas e violáceas. A verdadeira é a Evea ipecacuanha, Stam. (N. T.). (Burton, 1941: 267) ${ }^{7}$

Lacombe ratifica parte da informação de Burton, mas a corrige, especificando que há apenas uma verdadeira poaia, cujo nome científico sequer é mencionado pelo autor. Curiosamente, Lacombe repete a palavra cunha, sem o til.

Em outros casos, a retificação aproxima-se da nota explicativa, como no trecho em que Burton afirma que Mantiqueira significa "ladroeira" ou seria derivada de "Manta, capa de lã, e, em sentido figurado, ardil trapaça" (Burton, 1941: 120); em nota, Lacombe retifica o dado, ou acrescenta: "Th. Sampaio prefere deriva-la de amãty-kir, donde o nome primitivo da Serra: Amantiquira. Significaria então - a chuva goteja - como alusão à constância das nuvens chuvosas sobre o dorso da cordilheira. (N. T.)".

Na segunda edição "cunha" é alterada para "cuhã" [sic]; a nota do tradutor recebe um acréscimo: "Escrevia-se outrora ipicacuem, diz Teodoro Sampaio, que decompõe o termo em ypy-caá-guee e traduz: "a raiz vômica”, pois que ypy é raiz, o pé da planta e quee [sic] é vomitar. Há quem escreva ipecaconha, que quer dizer o pênis do pato, pois há semelhança da planta vomitiva (Cephalis ipecacuanha) com a forma do membro desta ave" (Burton, 1983: 249).

TRADTERM, 17, 2010, p. 67-84 
Em alguns casos, entretanto, o tradutor corrige o termo usado por Burton no texto, mas apõe uma nota indicando como estava no texto de partida. Não se explicita que o autor teria errado, mas o equívoco fica implícito em nota. Por exemplo, no corpo do texto lê-se Serra dos Coroados, mas há uma nota de Lacombe explicitando que "no Original está Serra dos Cerôados (N. T.)" (Burton, 1941: 120). No texto menciona-se a Serra do Grão Mogol, mas na nota assinala-se "no original 'Grão Mogor' (N. T.). (Burton, 1941: 118). Onde se lê Rio da Prata, há uma nota especificando que "no original está sempre 'Plata'. (N. T.)" (Burton, 1941: 298).

Essas notas são curiosas e provocam questões como "por que corrigir o texto, e não colocar em nota o supostamente correto?"; "se se corrige o texto, por dever didático, por que assinalar como estava no original?". São perguntas irrespondiveis, mas o procedimento pode levar o leitor a pensar que o tradutor é tão ou mais erudito que o autor. Verifica-se que os tradutores selecionados para fazer as traduções da Coleção Brasiliana, em geral, são da área de atuação do autor, por isso o destaque dado, nas capas das primeiras edições, ao nome do tradutor ou do redator do prefácio. Isso leva o leitor a confiar na tradução ou na "correção" feita pelo tradutor.

O procedimento, entretanto, pode ser perigoso, pois, por um lado, pode parecer um pouco arrogante para o leitor. E, por outro lado, nem sempre é adequado corrigir o autor, pois se pode incorrer também em erro; é o caso de Grão Mogol; de acordo com Chaves (s. d.), o lugar, antes de receber esse nome, era chamado de Santo Antonio e, depois, de Grão Mogor ${ }^{8}$.

Além disso, cumpre lembrar que Burton informa não ter revisado as provas do livro, editado por Isabel, sua esposa, na Inglaterra, quando ele viajava para o Paraguai. Isabel não era tão proficiente em língua portuguesa como era Burton.

8 Soares (1999: 494), em uma resenha da tradução de In Praise of Lies, de Patrícia Melo, considera arrogante a correção da referência a um texto bíblico citado por uma personagem: na leitura que faz, a referência incorreta seria "uma possivel ironia aos crentes e seus erros de referência bíblica". A observação de Soares indica que um "erro" pode receber outras interpretações.

TradTerm, 17, 2010, p. 67-84 
Em português no original

Há outro grupo de notas que apenas remetem a essa frase. É difícil classificar ou interpretar a razão dessas notas. Não são assinalados todos os segmentos em que Burton usa português muitos deles nem recebem tratamento gráfico especial, ou seja, não há como o leitor brasileiro saber que estariam em sua língua no "original".

As notas podem referir-se a uma construção ("Palacete da Comissão", por exemplo), a um sintagma nominal ("amarellão", "Paiz Camponez", "porta e janela", por exemplo), ou frases ("Não tem (pronouce "teng") errada", "Pode (pronounced paude) facilmente matar a todas", por exemplo). Pode-se pensar, por um lado, que as notas "em português no original" remetem à erudição do autor - um homem tão instruído que até conhece o português. Por outro lado, pode ser um gesto de autoafirmação da língua: o português é importante, tanto que um autor do porte de Burton conhece a lingua.

De acordo com o contexto político e intelectual da época e das duas décadas precedentes, a segunda interpretação pode ser mais plausivel. De acordo com De Luca (1999: 280), na "busca dos caracteres particularizantes da Nação fundiam-se o anseio de autonomia e afirmação ante o estrangeiro, manifesto no desejo de possuir uma língua própria". Nesse sentido, podemos pensar, ao ler que o autor usou o português, que um estrangeiro de tal vulto se curva diante da lingua portuguesa e a utiliza para se dirigir aos seus compatriotas, conferindo-lhe autoridade de língua de prestígio - os leitores estrangeiros teriam que deparar com e interpretar "nossa" língua.

\section{As notas que faltam}

Se temos inúmeras notas do tradutor indicando que certos trechos do livro estariam "em português no original", falta a contrapartida: assinalar quando um segmento está "traduzido no original". Essa falta já se evidencia no apagamento da tradução de parte do canto VI de Os Lusíadas feita por Burton, inserida, no texto de partida, entre o prefácio de Isabel Burton e o Ensaio

TradTerm, 17, 2010, p. 67-84 
Preliminar escrito por Burton. Tanto na primeira, quando na segunda edição da Brasiliana, são as cinco últimas estrofes do canto VI de Os Lusíadas de Camões que aparecem nessa mesma posição. Na primeira edição, sem qualquer anotação. Na segunda edição, há nota de Lacombe informando que Burton "foi um dos maiores camonistas em língua inglesa" e que "é autor de uma das melhores traduções" dos Lusíadas (Burton, 1983: 47). Constam as referências da tradução, publicada em 1880, mas não se informa que o poema aparece traduzido no texto de partida - o leitor pode interpretar que se trata de uma citação de Burton. Nessa segunda edição há um prefácio, em que Lacombe afirma que a tradução de Os Lusíadas feita por Burton é de "fidelidade extrema, prejudicada pelo seu sestro de empregar arcaísmos e palavras inventadas, sempre com o intuito de aproximar-se fielmente do original" ${ }^{\prime}$, mas observa que a tradução ressente-se "do fato de ter sido composta fragmentariamente por quem não era realmente poeta” (p.10).

São inúmeros os casos em que o autor traduz poemas, rimas ou letras de músicas. Por exemplo, no final do capítulo $\mathrm{XV}$, Burton faz a seguinte descrição do final de um jantar:

Immediately after the soup, each one made a little speech, and sang in the most nasal of tone a little scrap of a sentimental song, generally a quatrain and a bittock. The following are specimens:

Aos amigos um brinde feito

Reina a allegria em nosso peito

Grato licor, allegre, jucundo,

Que a tudo este mundo, desafria o Amor! [sic] §

All the audience takes up the last word, and joyously prolongs with a melancholy murmur - "Amo-o-o-r." Follows, perhaps: -

9 De acordo com Robinson (2002), Burton não seguiu um único método de tradução, mas buscava "'ser nativo', no sentido de 'ir na direção do autor original', como teriam dito os românticos alemães” (p. 259); isso explica a crítica de Lacombe aos "arcaismos" e à aproximação do original.

TRADTERm, 17, 2010, p. 67-84 
Como he grata a companhia, Lisonjeira a sociedade, Entre amigos verdadeiros, Viva a constante amizade Amizade! (chorus.) ॥

Nas notas, lê-se:

$\S \quad$ A toast to this good company,

Where every heart beats high with glee;

The generous wine flows fast and free,

For nought in all the world we see

That is not won by love

II How happily we here are met, how pleasantly the time hath passed Amid the friends we ne'er forget Ever may constant friendship last, And amity.

(Burton, 1869: 154)

Não se anuncia o "traduzido, no original" na tradução. Vou fornecer apenas mais um exemplo, para dar noção do cuidado que Burton tem com suas traduções. O poema abaixo é citado em nota sobre capivaras; o autor informa seus leitores que o animal aparece até mesmo na poesia e cita "Parábolas", de José Joaquim Corrêa de Almeida:

Assim procede o politico

Que os principios não extrema;

Calculadamente segue

Da Capivara o systema.

Thus proceeds the politician, Where principles go not too far; He right studiously pursues the System of the Capivár.

(Burton, 1869:41)

TradTerm, 17, 2010, p. 67-84 
Esse apagamento do trabalho meticuloso do tradutor Burton não pode ser explicado pela política editorial da Coleção, mas pode indicar que a estratégia de manter o tradutor invisivel - ou de silenciá-lo - não é promovida prioritariamente pelos editores e críticos, como aponta Venuti (2002), mas é esboçada, em um primeiro momento, pelos tradutores.

Talvez a invisibilidade do tradutor não seja exatamente uma estratégia e não seja necessariamente viabilizada pela prática da tradução fluente, mas também por outros métodos. No caso da tradução de Lacombe, a invisibilidade se dá pelo silenciamento da voz do autor-tradutor.

\section{Conclusão}

De acordo com Venuti (2002), a tradução é um elemento na construção de identidades nacionais. Nesse caso de uma tradução anotada, o direcionamento parece deliberado e com finalidades político-ideológicas identificáveis a partir da biografia do tradutor. Entretanto, o apagamento do autor-tradutor não parece em sintonia nem com o projeto editorial da Coleção Brasiliana, nem com as metas pedagógicas governamentais, com as quais o tradutor Lacombe compactuava, na medida em que foi Secretário do Conselho Nacional de Educação antes de fazer a tradução aqui analisada.

Se o nome do tradutor Lacombe está em evidência - seu nome está na capa do livro, assim como o de muitos outros tradutores dos livros da Coleção Brasiliana - seria coerente que não se apagasse o trabalho do autor-tradutor. Se há notas dedicadas apenas a indicar que trechos estavam em português no texto de partida, não haveria restrição editorial para incluir também notas que informassem "traduzido no original". Entretanto, na medida em que o trabalho do tradutor Burton é ocultado, há indícios que os nomes dos autores das traduções, notas e prefácios nas capas não fazem parte do projeto da Coleção Brasiliana para dar visibilidade à tarefa do tradutor. A indicação parece mais um meio de colocar em evidência que quem assina a tradução ou o prefácio é um intelectual de renome e erudição. Seria mais um aval para dar credibilidade intelectual

TradTerm, 17, 2010, p. 67-84 
à Brasiliana do que conferir respeito e dar visibilidade à tarefa do tradutor.

Finalmente, creio que as notas usadas como exemplo, ainda que poucas em relação à quantidade existente no texto de partida e na tradução, indicam que, mesmo que sejam concebidas para fechar os sentidos, indicar um caminho interpretativo, funcionam como dispersão e abertura à produção de novos sentidos.

\section{Referências Bibliográficas}

ARROJO, Rosemary (1992) Compreender x interpretar e a questão da tradução. In: (org.). O signo desconstruído: implicações para a tradução, a leitura e o ensino. Campinas: Pontes.

BURTON, Richard Francis (1869) Explorations of the highlands of the Brazil with a full account of the gold and diamond mines. London: Tinsley Brothers. (Replica Edition by Adamant Media Corporation, 2003).

(1868) Viagens aos planaltos do Brasil. Tradução de Américo Jacobina Lacombe. São Paulo: Companhia Editora Nacional, 1941. v. 1 .

. (1983) Viagens aos planaltos do Brasil. 2. ed. Tradução de Américo Jacobina Lacombe. São Paulo: Companhia Editora Nacional. 3 v.

CHAVES, M. L. S. C.; KARFUNKEL, J.; ADDAD, J. (1999). Geologia da região diamantífera de Grão Mogol (Minas Gerais). Geociências, Rio Claro, v. 18, n. 1, pp. 129-155.

CHAVES Mario Luiz de Sá Carneiro et al.(2008) Pedra Rica hill, Grão Mogol, State of Minas Gerais, Brazil. In: Geological and Palaeontological Sites of Brazil. Disponivel em: <http:/ /www.unb.br/ ig/sigep/sitio130/sitio130english.pdf>. Acesso em: 29 jun. 2008.

DE LUCA, Tania Regina (1999) A Revista do Brasil: um diagnóstico para a (N)ação. São Paulo: Ed. da UNESP, 1999.

DUTRA, Eliana de Freitas (2006) A nação nos livros: a biblioteca ideal na coleção Brasiliana. In: ; MOLLIER, Jean-Yves (org.). Politica, nação e edição: o lugar dos impressos na construção da vida política. São Paulo: Annablume, pp. 299-314.

PONTES, Heloísa (1989) Retratos do Brasil: editores, editoras e "Coleções Brasiliana” nas décadas de 30, 40 e 50. In: MICELI, Sergio.

TradTerm, 17, 2010, p. 67-84 
História das Ciências Sociais no Brasil. São Paulo: Revista dos Tribunais. v. 1, pp. 359-409.

RICE, Edward (1991) Sir Richard Burton: o agente secreto que fez a peregrinação a Meca, descobriu o Kama Sutra e trouxe as Mil e uma noites para o Ocidente. Tradução de Denise Bottmann. São Paulo: Companhia das Letras.

ROBINSON, Douglas (2002) Western translation theory: from Herodotus to Nietzsche. 2. ed. Manchester: St. Jerome.

SOARES, Luiz Felipe G. (1999) "In Praise of Lies de Patricia Melo". In: Cadernos de Tradução, Florianópolis, v. 4, pp. 461-465.

VENUTI, Lawrence (2002). Escândalos da tradução: por uma ética da diferença. Tradução de Laureano Pelegrin, Lucinéia Marcelino Villela, Marileide Dias Esqueda e Valéria Biondo. Bauru, SP: EDUSC.

TradTerm, 17, 2010, p. 67-84 